disturbance to the patient, the movement of whom is attended with the worst consequences. I have often used the different preparations of capsicum, with or without veratria and delphinia, in congestive fevers, with very good effect, and also in cases of cramp or spasm. This stimulative plan does not interfere with the administration of other medicines, but, on the contrary, greatly assists in restoring the lost power of the nervous energy and equalizing the balance of circulation. Russell-square, January, 1848.

\section{ULCERATION AND PERFORATION OF THE STOMACH.}

To the Editor of THe LANCET.

Srk,-The following fatal case has just fallen under my notice, and from the entire absence of all morbid symptoms until a few hours before death, it may be sufficiently interesting to deserve publication.-I am, Sir, your obedient servast, Westminster, Jan. 1848.

Geo. Burton Payne.

ON the 13th of January, 1848, I was called to see Elizabeth $\mathrm{B}-$, aged fifteen years. I found her in a state of extreme collapse, with large tympanitic abdomen, and she died a few moments after my visit. She had always been a somewhat delicate child, of spare habit, with fair hair and complexion; had lived regularly; was not accustomed to take ale or spirits, \&c., and had never complained of any pain, sickness, or disturbance of the digestive organs; appetite uniformly good; had not menstruated. She had been seized suddenly the day before, at about six P.M., with violent pain in the chest and stomach, having previously made a hearty dinner of boiled meat and vegetables. A little spirit was given to her by her mistress "for the wind." Not getting relief, she afterwards took senna mixture and castor oil, prescribed by a druggist, and went to bed. She suffered greatly during the night, but did not vomit or pass any motion. Early in the morning her abdomen began to swell, increasing until $I$ saw her at half-past three 0 'clock in the afternoon.

Post-mortem appearances.-Mr. Pearse, of Regent-street, Westminster, and myself, examined the body twenty-four hours after decease. Upon opening the peritonæal cavity, a large quantity of gaseous and fluid contents escaped; flakes of oil (evidently the castor oil) were floating upon the latter, and this at once suggested to our minds rupture or perforation of the ventricular coats. Upon touching the stomach, which was partially distended, more fluid escaped; it was then detached (no abnormal adhesions of its serous coat being present) and slit open along its lesser curvature. A circular perforation was observed, admitting the little finger through it on the posterior surface of the cardiac, and about one inch and a half equidistant from the cardiac orifice and the lesser margin; a little greyish undigested matter remained in the fundus. After washing the organ, its general appearance was seen to be natural, with the exception of two or three slight red striæ, leading towards the perforation; there were no puckering, thickening, or atrophy around it; the orifice resembled more a bullet-wound than anything else. The mucous lining generally was rather pulpy, readily giving way under the finger-nail, but unchanged in colour. The muscular coat also yielded to pressure; whilst the peritonæal investment peeled away easily from the circumference of the opening, presenting also a very fine dark-coloured ring around its edge. The remaining portions were perfectly normal. The greater lobe of the liver was indurated, and exceedingly pale on its surface; gall-bladder full; intestines distended with gas, and smeared over with patches of plastic lymph; the omentum was free from fat, and very vascular. The patient was by no means emaciated.

\section{CASE OF SPONTANEOUS EVOLUTION OF THE FETUS IN UTERO.}

\section{BY J. L. I'ON, Esq., M.R.C.S., London.}

SEEING a case of the above description recorded by $\mathrm{Mr}$. Vertue Edwards, at page 44 of the present volume of THF LANCET, and feeling convinced that there are some medical men who still entertain doubts of its occurrence, I take the liberty of reporting a case of a similar description, that lately came under the observation of myself and a brother practitioner in this neighbourhood.

At about seven o'clock P.M. of December 29th, 1847, I was requested by Mr. Berrell (a gentleman engaged in a very extensive midwifery practice in this locality) to assist him in a case of arm-presentation he had under his care. It required but a very superficial examination to be made acquainted with the nature and character of the presentation. The left arm protruded through the os externun, the liquor amnii had escaped, and the uterus had firmly contracted upon the body of the fœtus. It was in vigorous action at the time, although the gentleman before named had prudently premised the necessary operation, by the administration of a full dose of opium.

Before proceeding to the operation of turning, I suggested to $\mathrm{Mr}$. Berrell the propriety of introducing the catheter to relieve the bladder, in case it might be distended with urine. During the time he was engaged in effecting the suggestion, a violent and uniform contraction of the nterus supervened, which completely altered the state and condition of the case From this expulsive effort spontaneous evolution occurred; the nates were forced down to the os externum, and it was at once converted into a breech presentation. The subsequent steps of the proceeding do not require describing; the feet were quickly expelled, and the head followed immediately afterwards. The whole of the time occupied in the evolution and expulsion of the fœtus did not exceed five minutes. The pelvis of this patient was of an average capacity, but the child had ceased to breathe some time before its final expulsion.

As I before observed, I believe there are some practitioners who still doubt the possibility of spontaneous evolution, although, from the record of well authenticated cases, it is now more generally acknowledged. Nevertheless, we are not justified, I conceive, in leaving these cases to the unassisted efforts of Nature, nor should we be exonerated from making seasonable attempts to alter the position of the clild. This would be reasoning from the same erroneous premises as are adopted by those who have been converted to the modern theory propounded by Dr. Simpson and some others for the treatment of placenta prævia by the new method.

In my practice, extending over a period of twenty years, $I$ have met with only two cases of a similar description, and I must confess I should be sorry to make them a guide for my future conduct; I should still be influenced, in my practice, by what is found to be the general rule in such abnormal presentations.

This evolution was first of all noticed by Schoenheider; but Dr. Denman was the first, I believe, to call the attention of the profession to it in this country. He collected no less than thirty cases, and in the whole of these, only one child was born alive. The precise manner in which this favourable change takes place is still a disputed point amongst writers and teachers of obstetric medicine; and for all useful or practical purposes, it signifies little in what way Nature effects her purpose. I am convinced, nevertheless, from my own limited observation, that it can never take place unless the fundus of the uterus contracts with vigour and uniformity, and the body of the child be in some degree doubled upon itself.

As a piece of wholesome advice to younger practitioners, and as one which I myself have uniformly observed, I warn them, whenever they meet with a case of breech presentation, or one likely to become so, invariably to acquaint the friends and relatives of their patient of the nature of the case, and the moral certainty of the death of the child. It prepares their minds for the consequent disappointment, and confirms the confidence reposed in the nractitioner himself.

Westminster Bridge-road, January, 1848.

\section{REPORT OF A CASE OF PLACENTA PRAVIA.}

BY R. MARTIN, EsQ., M.R.C.S., Holbrook.

WhILE men of such eminence as Dr. Lee and Professor Simpson so materially differ on a subject of such vital importance as the treatment of placenta prævia, the publication of any case in point may have its advantage.

Harriet W-, a married woman, thirty-one years of age, and the mother of three children, in the ninth month of her fourth pregnancy, was, on the 4 th of November last, attacked with uterine hæmorrhage. This, by rest and other usual remedies, was kept in check till the 10th, when it returned with severity, and more or less continued till the 19th. At this date her medical attendant was summoned early in the morning. On his arrival the liquor amnii had been discharged, profuse hæmorrhage existed, and recurred at intervals throughout the day, followed by repeated attacks of syncope. At nine o'clock in the evening I was requested to visit her, in consultation. She had just sustained a fresh flooding, was 